\title{
O conhecimento sobre a violência de gênero entre estudantes de Medicina e médicos residentes
}

\author{
Knowledge about gender violence among medical \\ students and residents
}

Luciana de Morais Vicente ${ }^{\mathrm{I}}$

Elisabeth Meloni Vieira ${ }^{\mathrm{I}}$

PALAVRAS-CHAVE

- Violência contra a mulher.

- Gênero e saúde.

- Educação médica.

\section{KEY WORDS}

- Violence against women.

- Gender and health.

- Education, Medical.
Recebido em: 27/04/2006 Reencaminhado em: 10/03/2008 Aprovado em: 30/04/2008

\begin{abstract}
R E S U M O
Conhecer sobre violência de gênero e como manejar os casos éfundamental para o profissional de saúde colaborar na quebra do ciclo de violência. Este estudo teve por objetivo identificar o conhecimento de alunos de Medicina e de médicos residentes acerca dos aspectos epidemiológicos, éticos e legais da violência de gênero, bem como suas habilidades para identificar e manejar casos. Trata-se de um estudo quantitativo, de corte transversal, realizado por meio da aplicação de um questionário. Do total de 156 possiveeis respondentes, houve a participação de 104 (66,6\%). Destes, $77,8 \%$ (81) eram alunos e 22,1\% (23) médicos residentes. Notou-se predomínio dos participantes do sexo masculino $(61,7 \%, 58)$, com idades entre 22 e 24 (66,6\%/68). Receberam informação sobre como lidar com pacientes vítimas de violência de gênero $31,0 \%$ (32) dos participantes, sendo que $24,0 \%$ (25) tiveram aula sobre o tema; 63,1\% (65) julgavam-se capazes de ajudar uma mulher em situação de violência, mas apenas 16,8\% (17) haviam atendido algum caso na graduação. A maioria (89,1\%,90/101) acreditava queépapel do médico perguntar sobre violência. Do total de 100 participantes, 27\% foram considerados com baixo, 27\% com médio e $41 \%$ com alto conhecimento. Embora a maioria dos participantes conhecesse a definição de violência de gênero, bem como suas variações, com índices de acerto superiores a 74\% (77/104), muitos desconheciam a epidemiologia e suas taxas de morbi-mortalidade. Poucos foram identificados com habilidades para manejar casos. Encontrou-se maior conhecimento associado a maior experiência.
\end{abstract}

\section{A B S T R A C T}

Knowledge about gender violence and how to manage actual cases is crucial for health professionals to help break the circle of violence. The current study aimed to identify the levels of knowledge among medical students and residents concerning epidemiological, ethical, and legal aspects of gender violence, as well as their skills in identifying and managing cases. This was a quantitative, cross-sectional study using a questionnaire. From a total of 156 possible respondents, 104 (66.6\%) participated. Of these, 77.8\% (81) were medical students and $22.1 \%$ (23) residents. There was a predominance of male participants $(61.7 \%, 58)$, ranging from 22 to 24 years of age $(66.6 \%, 68)$. About one-third, or $31.0 \%$ (32) of the participants had received information on how to manage cases of gender violence, while $24.0 \%$ (25) had received classes on the theme; $63.1 \%$ (65) felt they were capable of helping a woman who had suffered such violence, but only $16.8 \%$ (17) had actually dealt with a case during their undergraduate training. The majority $(89.1 \%, 90 / 101)$ believed that it is the physician's role to inquire about violence. Self-assessed levels of knowledge were as follows: low - 27\%; medium-27\%; and high- $41 \%$. Although most respondents were able to define gender violence and its variations, with $74 \%$ of correct answers (77/104), many were unfamiliar with its epidemiology and morbidity and mortality rates. Few respondents were identified who had the requisite skills to manage cases. Knowledge was directly related to experience. 


\section{INTRODUÇÃO}

A violência contra a mulher é conceituada como violência de gênero e se caracteriza por qualquer ato que produza dano ou sofrimento físico, sexual ou psicológico à mulher, incluindo ameaças, coerção e privação de liberdade, assim como castigos, maus-tratos, pornografia, agressão sexual e incesto ${ }^{1}$. Foi o movimento feminista que primeiro denunciou, no Brasil, a violência de gênero e lutou para abolir sua invisibilidade social, gerando as primeiras ações de apoio e intervenção. Data de 1985 a iniciativa de envolvimento do Estado na questão com a criação da primeira Delegacia de Polícia de Defesa da Mulher, na cidade de São Paulo. Várias outras se seguiram com o objetivo específico de atender mulheres nessa situação, como o Centro de Orientação Jurídica (Coje), em 1986 e, posteriormente, o primeiro abrigo para mulheres em situação de risco de vida (Comvida).

Considerar a violência de gênero como problema de saúde e para o setor saúde ${ }^{2}$, entretanto, só ocorre quando a Organização Mundial da Saúde (OMS) estabelece este conceito ${ }^{3}$. A violência de gênero representa um sério problema de saúde pública por sua magnitude, acarretando lesões somáticas, dor, sofrimento e morte, além de agravantes psicológicos ${ }^{4}$. Demonstrou-se que a dor pélvica crônica está intimamente associada à violência de gênero ${ }^{3}$. Altos índices de suicídio abuso de drogas e álcool e queixas somáticas vagas (mialgias, cefaléias e outras dores crônicas) são sinais e sintomas comuns na mulher agredida, persistindo por longa duração o efeito negativo em sua saúde mesmo após o término da violência ${ }^{4}$.

Estudo realizado pela OMS, em vários países do mundo, inclusive no Brasil, mostra que entre 13\% (Japão) e 61\% (Peru) das mulheres já sofreram algum tipo de violência física alguma vez na vida, enquanto de $4 \%$ a $46 \%$ delas já foram forçadas a ter relações sexuais contra a vontade ${ }^{5}$. Em nosso país, 27,2\% das mulheres na cidade de São Paulo e 33,7\% das mulheres na zona da mata pernambucana relataram algum tipo de violência cometida por parceiro íntimo ou ex-parceiro ${ }^{6}$. Outros estudos, em outras partes do País, comprovam essa triste realidade $\mathrm{e}^{1,7,8}$.

\section{A violência de gênero no serviço de saúde}

As pesquisas mostram prevalências mais altas de violência em mulheres usuárias de serviços de saúde, fato relacionado às suas queixas e busca de ajuda ${ }^{9}$. Estudo conduzido na cidade de São Paulo com 3.193 usuárias de serviço de saúde mostrou que $55 \%$ relatavam pelo menos um episódio de violência física ou sexual na vida perpetrada por qualquer tipo de parceiro ${ }^{10}$.

Entre os entraves para uma abordagem adequada da violência de gênero, salienta-se a relutância da vítima em confidenciar ao profissional de saúde os incidentes vividos ${ }^{11}$. Para todas as mulheres de um estudo brasileiro que sofreram violência algu- ma vez na vida, apenas 2,5\% delas relataram a violência de gênero para médico ou profissional de saúde ${ }^{8}$. Acresce, ainda, existir certa relutância, por parte dos profissionais de saúde em pesquisar ativamente a violência de gênero ${ }^{12}$. Seja por subestimar a prevalência da violência de gênero ou por terem dúvidas sobre como atuar em relação à situação vivida pelas pacientes, os profissionais de saúde desistem de uma abordagem mais direta, evitando a anotação no prontuário ou simplesmente ignorando sinais e sintomas de violência ${ }^{13}$. É importante lembrar que parte desses profissionais pode ter dificuldades para questionar a paciente sobre possível violência de gênero por medo de ofendê-la ou por não acreditar que a violência é problema que compete à área da saúde. Sentimentos de frustração e impotência relativos à resolução dessa situação também causam dificuldades na interação com a paciente, particularmente se considerada a realidade do diminuto tempo para o atendimento médico, aliado à falta de preparo para a abordagem adequada do assunto ${ }^{12}$. Ter sido vítima ou perpetrador da violência pode também ser fator impediente para o profissional na detecção do problema ${ }^{14}$. Esses fatores explicam a pouca identificação de violência de gênero na prática clínica, bem como a orientação inadequada ${ }^{13}$, apesar das inúmeras delegacias e centros especializados.

\section{Aspectos legais e éticos da violência de gênero}

Recentemente estabeleceu-se a notificação compulsória de casos de violência contra a mulher, atendidos em serviços de saúde públicos ou privados, em vigor desde 24 de março de $2004^{15}$. A Lei 9.099/95, que considerava a violência de gênero crime de menor potencial ofensivo, certamente contribuiu para as vítimas postergarem pedidos de ajuda e denúncia de seus agressores. As penas, usualmente, consistiam na entrega de cestas básicas a uma instituição necessitada ou no pagamento de pequena multa, frequentemente de $\mathrm{R} \$ 60,00^{16}$. De grande mérito foi à recente promulgação da Lei 10.886, em 17 de junho de 2004, que acrescentou ao art. 129 do Código Penal os seguintes parágrafos:

$\S 9^{\circ}$ Se a lesão for praticada contra ascendente, descendente, irmão, cônjuge ou companheiro, ou com quem conviva ou tenha convivido, ou, ainda, prevalecendo-se o agente das relações domésticas, de coabitação ou de hospitalidade: Pena-detenção, de 6 (seis) meses a 1 (um) ano. $\S 10^{\circ}$ Nos casos previstos nos $\S \S 1^{\circ}$ a $3^{\circ}$ deste artigo, se as circunstâncias são as indicadas no $\S 9^{\circ}$ deste artigo, aumenta-se a pena em 1/3 (um terço).

O aumento da consciência social voltada à situação da mulher no contexto da violência tem contribuído, sobremaneira, 
para desmistificar o assunto. Entretanto, ainda existem limites na capacidade dos profissionais de saúde em reconhecer e lidar com o problema. Assim como em outros setores, existe preconceito no meio médico em relação à paciente que vive em situação de violência. Seja porque, na interpretação do médico, a paciente aceita a violência, pois permanece se relacionando com o agressor, seja porque quer ou gosta da agressão. $\mathrm{Ou}$, ainda, porque a situação trazida na consulta evoca sentimentos que o médico procura omitir, a fim de se esquivar do que não reconhece como diagnóstico e que não foi habilitado para manejar.

Surgem dúvidas sobre como ajudar a paciente. Não há clareza na determinação de quão abrangentes as atitudes durante a consulta devem ser. Deve-se instigar a denúncia? Deve-se denunciar a violência? Denunciá-la para quem? Incentivar a mulher a deixar seu parceiro? Sabe-se sobre abrigos e funcionamento de delegacias de defesa da mulher? Eticamente, como lidar com o relato de violência de gênero?

Responder às questões apontadas é fundamental para se buscar uma abordagem apropriada à vítima de violência de gênero, $\mathrm{e}$, para respondê-las, os profissionais da saúde requerem treinamento apropriado.

As unidades de saúde devem contar com profissionais capacitados em utilizar instrumentos, como protocolos de identificação e prevenção de DST/aids e gravide ${ }^{17}$, assim como abordar adequadamente cada caso, lançando mão dos recursos da comunidade e de outras áreas, como serviços jurídicos, policiais, psicológicos, grupos de apoio e autoajuda ${ }^{18}$.

É fundamental buscar um sistema de atendimento que ofereça abordagem integral da violência de gênero. Não há soluções e nem meios fáceis de resolvê-la exclusivamente por meio do sistema de saúde, mas se pode encontrar no desenvolvimento de habilidades médicas mais adequadas um importante aliado na quebra do ciclo de violência.

\section{OBJETIVOS}

Este estudo teve por objetivo identificar o conhecimento de alunos do último ano de graduação e de médicos residentes acerca dos aspectos epidemiológicos, éticos e legais referentes à violência de gênero, bem como suas habilidades para identificar e manejar esses casos de violência. Opiniões dos entrevistados sobre a violência foram pesquisadas, mas não é objeto deste artigo.

\section{MÉTODOS}

Trata-se de um estudo quantitativo, de corte transversal, realizado por meio da aplicação de um questionário com 49 perguntas aos acadêmicos de Medicina que cursavam o sexto ano em
2005 e aos médicos do primeiro ano de residência em ginecologia e obstetrícia, clínica médica ou medicina comunitária da Faculdade de Medicina de Ribeirão Preto da Universidade de São Paulo no ano de 2004.

O questionário foi desenvolvido após ampla revisão bibliográfica sobre o tema e consulta à literatura específica sobre elaboração de questionários ${ }^{19,20}$. Na folha de rosto, além do título da pesquisa, constava uma explicação sobre participação voluntária, garantindo a preservação do anonimato e confidencialidade das informações. O questionário continha três seções: a primeira abrangia o conhecimento de violência de gênero, suas definições, se e onde o participante teve aula específica sobre o tema, sua epidemiologia e morbi-mortalidade, condutas médicas, manejo de casos e aspectos legais e éticos referentes à paciente que vive em situação de violência. Também se perguntou ao participante se este se julgava capaz de ajudar pacientes nessa situação, se atendeu algum caso na graduação e se acreditava ser papel do médico perguntar sobre violência. Essas variáveis foram compiladas da literatura técnica e científica sobre o tema em artigos científicos, código penal, código de ética, artigos técnicos e manuais de treinamento $8,12,17,21-24$. As questões eram do tipo "marque a alternativa verdadeiro (V) ou falso (F)", havendo ainda a opção "não sei". A segunda parte do questionário abordou as opiniões dos entrevistados sobre a violência de gênero. Na última seção, houve coleta de informações sociodemográficas, como idade, sexo, cor/raça, religião e estado marital, baseada no formulário utilizado pelo Imposto de Renda.

Para avaliar a inteligibilidade, clareza e tempo de duração da aplicação do questionário à população do estudo, realizou-se um pré-teste entre dez alunos do sexto ano em 2004.

Cento e cinquenta e seis participantes (108 alunos e 48 médicos residentes) foram convidados a responder o questionário. $\mathrm{O}$ grupo de 108 alunos do sexto ano de Medicina foi abordado em cinco subgrupos organizados pela Comissão de Graduação da referida faculdade. Já os 48 residentes foram abordados ora em dupla, ora individualmente, de acordo com as escalas de plantão fornecidas pelos respectivos departamentos.

O questionário foi autoaplicado, sempre, em local em que se respeitasse a privacidade dos participantes e mediante a autorização prévia dos responsáveis pelo serviço, bem como do Comitê de Ética em Pesquisa do Hospital das Clínicas da Faculdade de Medicina de Ribeirão Preto da Universidade de São Paulo e da Comissão de Graduação, entre 17 de janeiro e 27 de fevereiro de 2005. Para garantir o anonimato dos participantes e evitar seu constrangimento durante a aplicação dos questionários, foi distribuído um par de 
envelopes em que depositavam seus questionários e seus termos de consentimento, respectivamente.

A variável conhecimento compõe-se de um conjunto de 24 afirmações para o qual se elaborou um escore. Para cada resposta correta o participante ganhou um ponto. Para o conhecimento da definição de violência de gênero, o valor de pontos variou de 0 a 4; para o conhecimento dos aspectos éticos e legais, variou de 0 a 5; para o conhecimento da epidemiologia e morbi-mortalidade da violência de gênero, variou de 0 a 4 pontos; para o conhecimento de condutas médicas, variou de 0 a 11 pontos. O escore total, somando todos os pontos, foi denominado conhecimento geral, que variou de 0 a 24 pontos.

Na digitação dos dados utilizou-se o programa Epi Data 3.1, eo processamento foi realizado em STATA 5.0. Buscou-se associação estatística entre as variáveis que definiam o conhecimento, a condição de aluno ou residente, se teve aula específica sobre o tema, se acreditava ou não ser papel do médico perguntar ou não sobre violência, se atendeu caso de violência na graduação, sexo, cor/raça e estado marital. Para isto, utilizou-se a análise bivariada, aplicando-se o teste de qui-quadrado e o teste exato de Fisher, sendo a hipótese de associação aceita quando p fosse menor ou igual a 0,05.

\section{RESULTADOS}

Do total de 156 possíveis respondentes houve a participação de 104 (66,6\%). Ao final da aplicação do questionário, as não respostas somaram $24,3 \%$ (38) da população do estudo, sendo que 27 alunos e 11 residentes deixaram questionários em branco. Outros $9,6 \%$ (14 residentes) se recusaram a participar da pesquisa no momento em que foram abordados. $\mathrm{O}$ índice de perda nas questões variou de $0,96 \%$ (1) a 1,92\% (2). Por ter sido autoaplicado, em muitas questões existem algumas não respostas.

Desses 104 participantes, 77,8\% (81) eram alunos e 22,1\% (23) médicos residentes (11 da ginecologia e obstetrícia, 9 da clínica médica e 3 da medicina comunitária). Aidade média dos participantes era de 24,37 anos, e a idade mediana, 24 . Notou-se o predomínio dos participantes na faixa de 22 a 24 anos-61,7\% (58). A maioria 66,6\% (68) é do sexo masculino, enquanto apenas 33,3\% (34) são do sexo feminino (2 não responderam). Declararam-se brancos 81,3\% (83), enquanto os não-brancos somaram 18,6\% (19) (2 não responderam). Os católicos somaram 57,6\% (60), declararam-se adeptos de outras religiões 20,1\% (21), e 22,1\% (23) declararam não ter religião. Os que se declararam adeptos de outras religiões incluem protestantes, evangélicos e religiões orien- tais. A maioria é solteira, 93,1\% (95), e os demais 6,8\% (7) moram junto ou são casados (2 não responderam).

Declararam ter recebido qualquer tipo de informação sobre como lidar com pacientes vítimas de violência de gênero 31\% (32) dos participantes. Outros 68,9\% (71) alegaram nunca ter recebido este tipo de informação. Somente $24 \%$ (25) tiveram aula sobre o tema, enquanto 75,9\% (79) disseram nunca ter assistido à aula sobre violência de gênero. Dos participantes que declararam ter assistido à aula específica sobre violência de gênero, 84,2\% (16) relataram ter assistido a essa aula na disciplina de medicina legal e 15,7\% (3) na disciplina de medicina social. Nenhum participante referiu aula específica em outra disciplina.

Do total de 103 participantes 63,1\% (65) julgavam-se capazes de ajudar uma vítima de violência de gênero, enquanto $37,6 \%$ (38) admitiram não serem capazes. Perguntados se haviam atendido algum caso de violência na graduação, dos 101 que responderam a esta questão 16,8\% (17) disseram que sim e 83,1\% (84) disseram que não. A maioria $(89,1 \%, 90 / 101)$ acreditava que é papel do médico perguntar sobre violência, enquanto $10,8 \%$ $(11 / 101)$ acreditavam que não.

\section{Conhecimento sobre violência de gênero}

A variável denominada conhecimento geral teve média de 12,1 pontos, sendo 23 o número máximo de pontos alcançado e 1 o número mínimo. O ponto de corte foi dado pela mediana, que atingiu 12 pontos. Do total de 100 participantes, 27\% foram considerados com baixo conhecimento (10 pontos ou menos), $27 \%$ com médio conhecimento (de 11 a 13 pontos) e 41\% com alto conhecimento (14 pontos ou mais).

A Tabela 1 mostra que a maioria dos participantes conhece a definição de violência de gênero, bem como suas variações, como mostram os índices de acerto superiores a 74\% (77/104), mas para muitos parece que não havia clareza entre violência de gênero e violência doméstica, sobre a qual houve apenas 44,2\% (46/104) de acerto. Muitos participantes desconheciam a epidemiologia e as taxas de morbi-mortalidade de violência de gênero. Houve apenas $20,3 \%(21 / 103)$ de acertos quanto à prevalência de violência de gênero, 31\% (32/103) de acertos quanto à frequência de lesão corporal na violência de gênero, apenas 18,3\% (19/104) de acertos com relação à frequência de relatos de abusos durante as consultas de pré-natal e 39,4\% (41/104) acertaram a porcentagem de pacientes que relatam ao médico estar sofrendo abuso. 
Tabela 1

Conhecimento dos conceitos que definem violência de gênero de alunos de Ciências Médicas da FMRP - USP e residentes de especialidades de ginecologia e obstetrícia (GO), Medicina de Família e Clínica Médica da FMRP -

USP, 2005

\begin{tabular}{lcc}
\hline Afirmações & No acertos $^{\%}$ acertos \\
\hline $\begin{array}{l}\text { Violência contra uma mulher cometida por parceiro íntimo com quem ela mantém relação de afeto } \\
\text { é violência de gênero. }\end{array}$ & 77 & 74 \\
Violência de gênero é qualquer violência cometida dentro do lar por algum membro da família. & 46 & 44,2 \\
$\begin{array}{l}\text { Menosprezar, humilhar constantemente ou intimidar uma mulher podem ser consideradas } \\
\text { variantes da violência contra a mulher se cometidas por parceiro íntimo. }\end{array}$ & 90 & 86,5 \\
$\begin{array}{l}\text { Empurrões e bofetadas ocasionais são formas de violência de gênero quando cometidos contra a } \\
\text { mulher por parceiro íntimo. }\end{array}$ & 78 & 75 \\
\hline
\end{tabular}

A Tabela 2 indica que a maioria dos participantes, 99\% (102/103), concordou em que não se devem ignorar sinais de violência, mesmo quando a paciente não menciona o assunto, $72,8 \%$ (75/103); que marcar retornos em intervalos curtos é uma boa estratégia para ajudar mulheres em situação de violência; $84,4 \%(87 / 103)$ concordou em que não se deve prescrever medicação ansiolítica ou antidepressiva para mulheres em situação de violência; $68,9 \%$ (71/103) concordou em que é correto o médico perguntar sobre a possível existência de violência; $85,4 \%$ (88/103) dos participantes ofereceriam o telefone da Delegacia de Defesa da Mulher e endereço de casa-abrigo para pacientes sabidamente em situação de violência de gênero. Apenas 22,3\% $(23 / 103)$ aconselhariam a mulher a deixar o parceiro violento imediatamente. A tabela mostra também que somente $30 \%$ (31/103) realizariam notificação compulsória do fato, embora quase a metade conheça a necessidade de notificação. Muitos erroneamente recomendariam terapia de casal e pediriam que o parceiro violento viesse ao serviço para uma conversa, e muitos, $37,8 \%$ (39/103), não souberam responder essa questão, evidenciando o desconhecimento da conduta correta diante de pacientes em situação de violência.

A Tabela 2 torna evidente que muitos dos respondentes não têm habilidade para manejar casos de violência de gênero, pois o índice de acerto para o conhecimento do funcionamento de casa-abrigo foi de $20,3 \%$ (21/103), enquanto o acerto do endereço da Delegacia de Defesa da Mulher foi de 5,8\% (6/103). Vê-se também que quase todos desconheciam a Lei 10.886, pelo índice de $0,9 \%(1 / 103)$ de acertos, assim como muitos desconheciam as penalidades para o perpetrador de violência de gênero, com $25,4 \%$ (26/102) de acertos. Menos da metade dos respondentes conheciam $(44,1 \% ; 45 / 102)$ o que rege o código de ética médica em casos de violência de gênero.

\section{Associação entre variáveis}

Não foi encontrada associação entre conhecimento sobre violência de gênero e idade, sexo, estado marital, cor/raça ou ter assistido a aula sobre o tema.

Como mostra a Tabela 3, encontrou-se associação entre ter atendido alguma vítima de violência na graduação e ter apresentado alto conhecimento: $69 \%$ dos que atenderam algum caso apresentaram alto conhecimento, comparado com $38 \%$ dos que não atenderam (Fisher $\mathrm{p}<0,04$ ). 
Tabela 2

Conhecimento da conduta médica correta diante de uma paciente que é, possivelmente, vítima de violência de gênero dos alunos de Ciências Médicas da FMRP - USP e residentes da FMRP - USP, 2005, Ribeirão Preto

Sobre a conduta médica diante de uma paciente que é, possivelmente, vítima de violência cometida por parceiro íntimo:

No $\quad \%$

O médico deve, sempre que houver oportunidade, perguntar para a paciente sobre

comportamento violento de seu parceiro (V).

71

68,9

O médico deve ignorar hematomas ou outros sinais de violência enquanto a paciente não tocar no assunto $(\mathrm{F})$.

Marcar retorno em intervalos menores que um mês quando suspeitar que a paciente sofre violência em casa $(\mathrm{V})$.

Prescrever calmantes/antidepressivos para a paciente conseguir lidar com os possíveis problemas que tem em casa $(\mathrm{F})$.

Quando há indícios de violência contra a mulher cometida por parceiro íntimo, o médico:

Deve aconselhar a paciente a deixar seu parceiro imediatamente $(\mathrm{F})$.

Deve propor que a paciente elabore um plano de segurança para ela e para seus filhos (V).

Recomendar terapia de casal (F).

Dar número de telefone de abrigo para mulheres e de delegacias da mulher para a paciente (V).

Sugerir que a paciente traga o parceiro na próxima vinda ao serviço de saúde junto com ela para conversarem $(\mathrm{F})$.

Deve realizar a notificação compulsória por se tratar de crime (V).

Uma vez que a informação é sigilosa, não se deve notificar o fato (F).

\section{Conhecimento legal do manejo de casos}

Para abrigar-se numa casa-abrigo, a mulher que vive em situação de violência precisa de um boletim de ocorrência obrigatoriamente (V).

A Delegacia de Defesa da Mulher de Ribeirão Preto fica na Rua General Osório, 548 (F).

A Lei 10.886 considera passível de detenção por até quatro anos o perpetrador de violência contra a mulher $(\mathrm{V})$.

Até 2004, a penalidade para a maioria dos praticantes de violência contra a mulher consistia em entregar uma cesta básica para alguma entidade de caridade (V). 


\section{Tabela 3}

Níveis de conhecimento sobre violência de gênero e atendimento de casos na graduação, condição de aluno ou residentes, acreditar no papel do médico e ter atendido casos na graduação, Ribeirão Preto, 2004

\begin{tabular}{|c|c|c|c|c|c|c|c|c|}
\hline \multirow[b]{3}{*}{ Tipos de conhecimento } & & \multirow[b]{3}{*}{$\mathrm{p}$} & \multicolumn{6}{|c|}{ Níveis de Conhecimento } \\
\hline & & & \multicolumn{2}{|c|}{ Baixo } & \multicolumn{2}{|c|}{ Médio } & \multicolumn{2}{|c|}{ Alto } \\
\hline & & & $\mathrm{N}^{\mathrm{o}}$ & $\%$ & $\mathrm{~N}^{\circ}$ & $\%$ & $\mathrm{~N}^{\circ}$ & $\%$ \\
\hline Conhecimento geral de VG & & 0,04 & & & & & & \\
\hline \multirow{2}{*}{ Atendimento na graduação } & $\operatorname{sim}$ & & 1 & 6 & 4 & 25 & 11 & 69 \\
\hline & não & & 26 & 33 & 23 & 29 & 30 & 38 \\
\hline \multirow{3}{*}{ Conhecimento epidemiológico de VG } & & 0,023 & & & & & & \\
\hline & alunos & & 33 & 41,2 & 14 & 17,5 & 33 & 41,2 \\
\hline & residentes & & 3 & 13,6 & 8 & 36,3 & 11 & 50,1 \\
\hline Conhecimento de condutas médicas em VG & & 0,04 & & & & & & \\
\hline \multirow{3}{*}{ Acredita ser papel do médico perguntar sobre VG } & $\operatorname{sim}$ & & 28 & 31,1 & 22 & 24,4 & 40 & 44,4 \\
\hline & não & & 4 & 36,4 & 6 & 54,5 & 1 & 9,1 \\
\hline & & 0,014 & & & & & & \\
\hline \multirow{2}{*}{ Atendeu paciente vítima de VG na graduação } & $\operatorname{sim}$ & & 4 & 23,5 & 1 & 5,8 & 12 & 70,5 \\
\hline & não & & 28 & 33,3 & 27 & 32,1 & 29 & 34,5 \\
\hline
\end{tabular}

Maior proporção de alunos apresentou baixo conhecimento acerca da epidemiologia e morbi-mortalidade da violência de gênero $(41,2 \%)$ comparando-se com os residentes $(13,6 \%$ ) (Fisher $\mathrm{p}=0,023)$.

Maior conhecimento das condutas médicas a tomar diante de pacientes vítimas de violência de gênero aumenta a chance de o médico perguntar sobre situações violentas a suas pacientes. Acreditar ser papel do médico perguntar sobre violência de gênero foi encontrado associado ao maior conhecimento sobre o tema (Fisher $\mathrm{p}<0,040$ ). Ter atendido caso de violência de gênero foi encontrado associado a maior conhecimento das condutas médicas nesses casos: 70,5\% dos que atenderam casos na graduação apresentaram maior conhecimento (Fisher $p<0,014$ ).

\section{DISCUSSÃO}

Oalto índice de não resposta $(24,3 \%)$ e recusas $(9,3 \%)$ neste estudo pode significar, além da falta de tempo ou disponibilidade para responder, desconhecimento da importância do tema ou sua não valorização.
Estudo conduzido nos Estados Unidos ${ }^{12}$ mostrou que 50\% dos médicos acreditavam que a violência de gênero era algo muito raro, atingindo apenas $1 \%$ da população. Partindo do pressuposto de que os respondentes são os que mais valorizam o tema, ainda assim encontramos menos da metade ( $41 \%)$ deles com alto conhecimento sobre violência de gênero. Por outro lado, comparando-se alguns resultados com os de outras pesquisas, verifica-se que alguns resultados deste estudo mostram porcentagens de acertos similares ou maiores do que os encontrados na literatura: em relação a ser papel do médico perguntar sobre violência, $89,1 \%$ responderam que sim, enquanto em outro estudo ${ }^{12}$, $85 \% ; 63,1 \%$ de nossos respondentes acreditavam-se capazes de ajudar, enquanto no outro estudo ${ }^{12}$ apenas $39,3 \%$ confiavam em sua capacidade de ajuda. Em relação ao manejo dos casos, 72,8\% de nossos respondentes disseram que recomendariam retornos curtos, enquanto em outro estudo ${ }^{24}$, realizado nos Estados Unidos com médicos residentes, apenas $42 \%$ adotariam esta estratégia. Em nosso estudo apenas 0,97\% (1/103) prescreveriam medicação ansiolítica ou antidepressiva, mas 14,5\% (15) não soube- 
ram responder esta questão, enquanto na literatura ${ }^{24} 12 \%$ prescreveriam este tipo de medicação. Em nosso estudo, 85,4\% ofereceriam telefone ou endereço de casa-abrigo (embora não soubessem corretamente este endereço), enquanto em outro estudo ${ }^{24}$ apenas $10 \%$ ofereceriam esse endereço. Entretanto, em outras respostas referentes ao manejo dos casos, encontrou-se maior porcentagem de erros do que citado na literatura. Alguns autores ${ }^{24}$ afirmam que a revelação da agressão pode ser perigosa para a mulher que vive cronicamente em situação de violência. Portanto, deve-se evitar aconselhá-la a deixar o parceiro, como sugerido por nossos respondentes $(22,4 \%)$, contra 3\% da literatura $^{24}$. Deve-se evitar pedir ao parceiro para vir ao serviço de saúde, como marcaram $18,4 \%$ de nossos respondentes contra $32 \%$ de outro estudo ${ }^{24}$, e recomendar terapia de casal (37,8\% de nossos respondentes contra $27 \%$ da literatura ${ }^{24}$ ). Essas respostas mostram que há maior despreparo para o manejo de casos entre nossos respondentes.

Uma importante característica observada no conhecimento sobre violência de gênero desses respondentes foi sua associação com o atendimento, o que mostra que atender casos de violência de gênero desperta a necessidade de compreender mais o fenômeno.

O quadro de violência de gênero só poderá ser mudado se conseguirmos convencer as instituições de saúde a se responsabilizarem por incentivar a notificação dos casos, criando uma rotina para que isso ocorra, atribuindo funções e responsabilidades aos mais variados profissionais da saúde. Também contribuirá oferecer cursos de capacitação para que os profissionais se conscientizem da responsabilidade ética e legal em que consiste a notificação, assim como incluir o tema nos currículos dos profissionais de saúde. Rodriguez et al. (1999) ${ }^{25}$ evidenciaram que, após treinamento específico em como lidar com pacientes vítimas de violência de gênero, $89 \%$ dos participantes rotineiramente indicavam casas-abrigo e $65 \%$ orientavam a denunciar o perpetrador violento.

\section{REFERÊNCIAS}

1. Kronbauer JFD, Meneghel SN. Perfil da violência de gênero perpetrada pelo companheiro. Rev. Saúde Pública 2005; 39 (5): 695-701.

2. Schraiber LB, D'Oliveira AFPL. Violência contra Mulheres: Interfaces com a Saúde. Interface - Comunicação, Educação 1999; 3 (5):1-27.

3. World Health Organization. Violence against women, health consequences. Geneva: WH O; 1997.

4. Campbell JC. Health consequences of intimate partner violence. The Lancet. 2002;359: 1331-1336.

5. World Health Organization. Multi-country study on women's health and domestic violence against women: summary report of initial results on prevalence, health outcomes and women's responses. Geneva: WHO; 2005.
6. Schraiber LB, D'Oliveira AFPL, Falcão MTC, Santos WF. Violência dói e não é direito: a violência contra a mulher, a saúde e os direitos humanos. São Paulo: Ed. UNESP; 2005.

7. Santos LL. A invisibilidade da Violência de Gênero em dois serviços de Atenção Primária à Saúde Ribeirão Preto, SP; 2003. Mestrado [Dissertação] - Universidade de São Paulo; 2003.

8. Marinheiro ALV. Violência doméstica: prevalência entre mulheres usuárias de um serviço de saúde de Ribeirão Preto - SP. Ribeirão preto, SP; 2004. Mestrado [Dissertação] Universidade de São Paulo.

9. Krug EG, Dahlberg LL, Mercy JA, Zwi A, Lozano R. (Ed.) Relatório Mundial obre violência e saúde. Genebra: Organização Mundial da Saúde; 2002.

10. Schraiber LB, Falcão MTC, D'Oliveira AFPL, Pinho AA, Hanada H, Felicíssimo AF, Kiss LB, Puccia MIR, Andrade MC, Batista KBC. Características da violência física e/ou sexual entre mulheres usuárias de serviços de saúde da Grande São Paulo. Ciênc saúde coletiva. 2003;8 (supl.1):149.

11. Gerbert B, Caspers N, Bronstone A, Moe J, Bercrombie P. A Qualitative analysis of how physicians with expertise in domestic violence approach the identification of victims. Ann Intern Med. 1999; 131(8):578-584.

12. Sugg NK, Thompson RS, Thompson DC, Maiuro R, Rivara FP. Domestic violence and primary care. Arch Fam Med. 1999;8:301-306.

13. Sugg NK, Inult T. Primary Care physicians' response to domestic violence: opening Pandora's box. JAMA 1992;267(23):3157-3160.

14. Lamberg L. Domestic violence: what to ask, what to do. JAMA 2000; 284(5):554-556

15. Lei 10.7787. Código Penal. 5 ed. São Paulo: Ed. Revista dos Tribunais; 2000.

16. Saffioti HIB. Violência estrutural de gênero: mulher gosta de apanhar? [online]. [acessado em: 22 jan. 2005]. Brasília, DF: Programa de Prevenção, Assistência e Combate à Violência contra a Mulher; 2003. Disponíuvel em: http:/ / www.presidência.gov.br/spmulheres/ct/livro.pdf.

17. Norma Técnica do Ministério da Saúde para a "Prevenção e Tratamento dos Agravos Resultantes da Violência Sexual contra Mulheres e Adolescentes". [online]; 1998. [acesso em: 12 nov. 2004]. Disponível em:http:/ / www.saude.gov.br.

18. Brasil. Ministério da Saúde. Violência intrafamiliar: orientações para a prática em serviço. Cadernos de Atenção Básica. Brasília:[S.n.]; 2002. n. 8 (Série A. Normas e Manuais Técnicos) 
19. Bowling A. Research methods in health: investigating health and health services. Buckingham-Philadelphia: Open University Press; 1997.

20. Oppenheim AN. Questionnaire Design, Interviewing and Attitude Measurement. London and Washington: Pinter Press; 1999.

21. Curso de capacitação para o atendimento a mulheres em situação de violência. Departamento de Medicina Preventiva da Faculdade de Medicina da Universidade de São Paulo, Coletivo Feminista Sexualidade e Saúde. [S.1]: Fundação Ford; 1997.

22. Grupo de Trabalho Movimento Popular da Mulher e Nzinga. Considerações e orientações para atendimento à mulher em situação de violência na rede pública de saúde. Jornal da Rede Nacional Feminista de Saúde e Direitos Reprodutivos. 1999; 19: 12-13.

23. Conselho Regional de Medicina do Estado de São Paulo. Código de Ética Médica.

24. Varjavand N, Cohen DG, Novack DH. An assessment of resident's abilities to detect and manage domestic violence. J Gen Intern Med 2002;17:465-468.

25. Rodriguez MA, McLoughlin E, Grumbach K. Screening and intervention for intimate partner abuse: practices and attitudes of primary care physicians. JAMA. 1999;282(5):468-474.

\section{CONTRIBUIÇÃO DOS AUTORES}

Luciana de Morais Vicente, bolsista do Cremesp (Conselho Regional de Medicina do Estado de São Paulo) no período de 2004-2005, elaborou o projeto de pesquisa, desenvolveu o instrumento de pesquisa, coletou os dados e digitou as informações no banco de dados, apresentadas em relatório final. Elisabeth Meloni Vieira orientou e supervisionou o estudo e a elaboração do instrumento, recomendou a bibliografia, conferiu a digitação e procedeu à análise e edição do relatório, tendo elaborado este artigo. Os autores agradecem ao Cremesp pelo apoio e à Prof. Dra. Lília Blima Schraiber por suas valiosas sugestões a este texto.

\section{CONFLITO DE INTERESSES}

Declarou não haver

\section{ENDEREÇO PARA CORRESPONDÊNCIA}

Elisabeth Meloni Vieira

Departamento de Medicina Social

Faculdade de Medicina de Ribeirão Preto - USP

Av. Bandeirantes, 3900

Monte Alegre

CEP.:14049-900 - Ribeirão Preto - SP

E-mail: bmeloni@fmrp.usp.br 